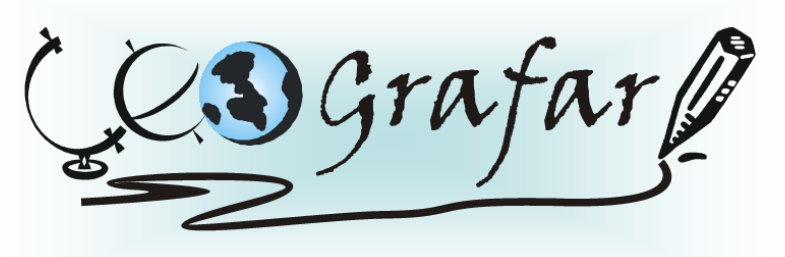

Revista Eletrônica do Programa de Pós-Graduação em Geografia - UFPR

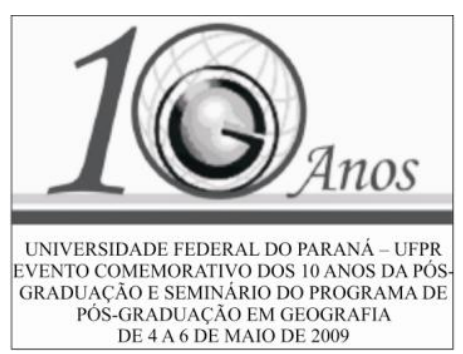

\title{
GEOMORFOLOGIA DA BACIA DO RIO PEQUENO, ANTONINA - PR: CARACTERIZAÇÃO PRELIMINAR
}

\author{
JULIO MANOEL FRANÇA DA SILVA ${ }^{1}$ \\ LEONARDO JOSÉ CORDEIRO SANTOS ${ }^{2}$
}

\section{LINHA DE PESQUISA: PAISAGEM E ANÁLISE AMBIENTAL}

\section{INTRODUÇÃ̃O}

A geomorfologia é a ciência que se ocupa em estudar as formas de relevo, analisando e interpretando sua configuração geométrica, sua gênese e os processos que nela atuam, além da interação dessas com os demais componentes do meio físico. A cartografia se constitui como um importante método para a pesquisa geomorfológica através da representação, comunicação e análise dos resultados obtidos em uma determinada área, sendo que, um mapa geomorfológico, além de sintetizar as informações obtidas em campo, gabinete e laboratório, pode servir como um instrumento para a análise do potencial de uso e ocupação do espaço geográfico, bem como indicar as áreas que devem se manter preservadas devido suas restrições físico-naturais ou importância ecológica.

Apesar da importância do mapeamento geomorfológico tanto cientificamente como aplicada aos planejamentos territoriais, à complexidade do objeto analisado torna difícil a tarefa de ser representado em um ou poucos documentos. Ademais, não existe um método unificado internacionalmente para a representação do relevo, e o que se verifica é a adoção de diferentes critérios nas escolas geomorfológicas do mundo, entre eles o estrutural, o climático, o têmporo-espacial e o genético (Christofoletti, 1980), impossibilitando uma padronização operacional, necessária para facilitar a transmissão das informações.

A presente pesquisa pretende contribuir para a taxonomia do relevo em escala de detalhe, mais especificamente da geomorfologia das planícies fluviais, havendo a necessidade

\footnotetext{
1 juliogeog@yahoo.com.br

2 Professor orientador - santos@ufpr.br
} 
de conhecer a gênese das mesmas, considerando aspectos geológicos, sedimentológicos, pedológicos e climáticos, de maneira a classificá-las e representá-las cartograficamente.

A área de estudo é a bacia do Rio Pequeno, localizada no município de Antonina, estado do Paraná, a qual faz parte da unidade fisiográfica denominada por Mack (1969) como Serra do Mar Paranaense (Fig. 1).

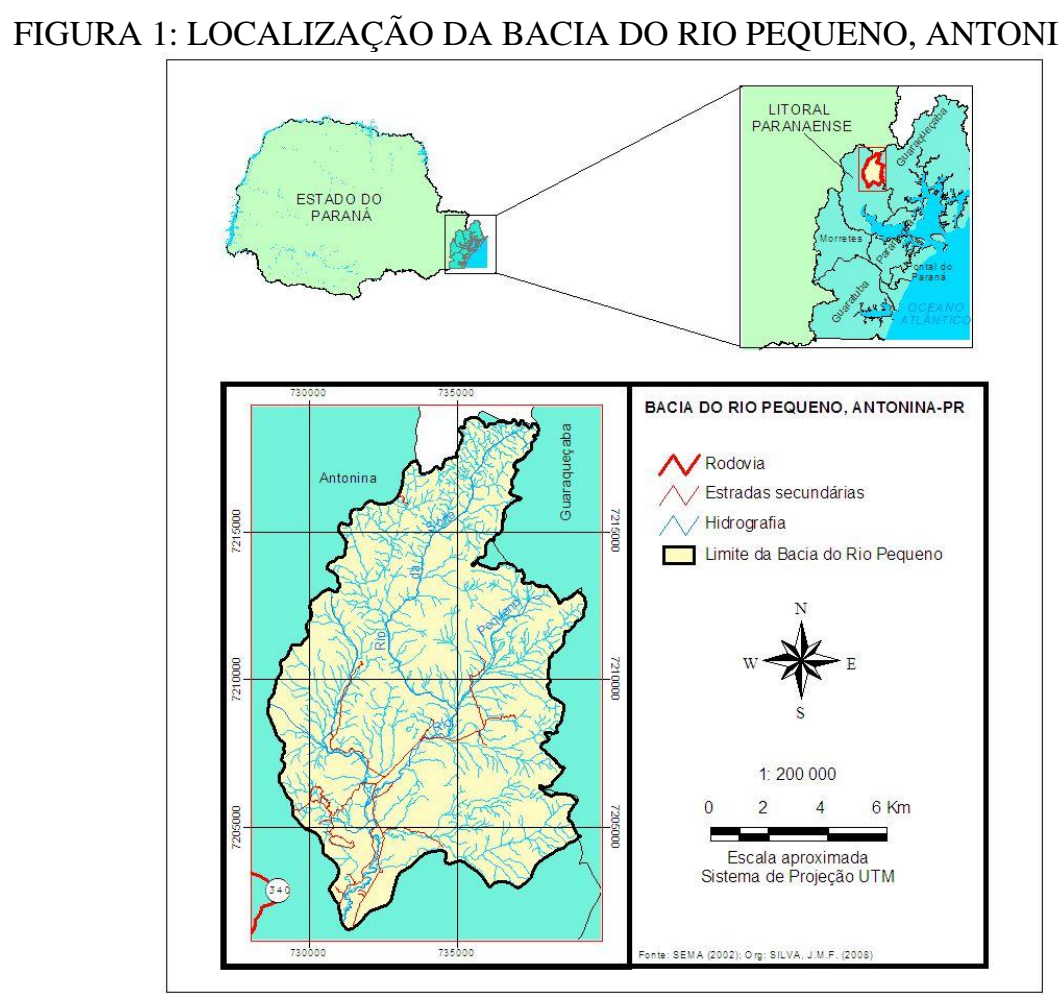

\section{CARTOGRAFIA GEOMORFOLÓGICA}

Desde que passou a ser utilizada na pesquisa geomorfológica, a cartografia encontrou em diferentes autores abordagens que buscaram estabelecer uma classificação das formas de relevo. Porém, os mapeamentos geomorfológicos ainda não seguem um padrão predefinido, tanto em relação às escalas adotadas, como quanto à adoção de bases taxonômicas a elas aferidas e apesar dos avanços tecnológicos que permitem uma análise cada vez mais detalhada das feições de relevo através de imagens de satélite e de radar e fotografias aéreas sistemáticas, ainda não existe consenso no estabelecimento taxonômico e consolidação teórica e metodológica para a representação cartográfica dessas formas.

Para o mapa geomorfológico de detalhe existem orientações genéricas, como as apresentadas por Demek (1967) segundo o qual o mapa geomorfológico de detalhe tem as seguinte funções: a) reconhecimento das formas de relevo que ocorrem na área mapeada; b) 
estabelecimento de medidas qualitativas e quantitativas das formas; c) elucidação de sua gênese através da determinação da correlação com materiais, processos morfodinâmicos e idade; e d) estabelecimento de seu arranjo espacial e de seu sistema de relações mútuas.

Para Coltrinari (1982) nas cartas geomorfológicas podem figurar categorias de fenômenos muito diferentes, tanto espacialmente como temporais, cuja representação dependerá da escala escolhida. Neste sentido, as cartas geomorfológicas de pequena escala (1: 500000 e menores) são utilizadas para a cartografação dos conjuntos de relevo de dimensões quilométricas, sendo que a influência das forças externas aparece de maneira restrita. As cartas de detalhe (1: 5000 a 1: 25 000) apresentam características distintas. De forma preferencial são focalizadas os processos que criam formas e o modelado. Podem figurar nessas cartas objetos de tamanho decamétrico (ex: terraços, nichos) e conjuntos de feições que atinjam essa dimensão (ex: campo de matacões), enquanto o relevo permanece em segundo plano (TRICART, 1965).

Pela natureza dos fatos representados, as cartas geomorfológicas de detalhe são cartas complexas, que imprimem muitos desafios técnicos para a sua elaboração. A complexidade se deve aos diversos tipos de informações, relativas às formas, que deve conter. Em primeiro lugar, deve figurar a morfometria, sendo que para isto, os dados fornecidos pelo fundo topográfico devem ser completados com elementos incorporados à representação das formas (altura de rebordos de terraço, de cornijas, de margem de rio, etc.). A morfografia diz respeito à necessidade de representar as formas de acordo com a sua morfologia própria, que decorre, em graus diversos, de suas gêneses. Por exemplo, um fundo de vale côncavo pode ter se originado de vários processos diferentes, combinados ou não entre eles. Pode-se estabelecer uma tipologia das formas, porém, sem ocultar a variabilidade dos indivíduos, para não ocorrer o risco de criar esquemas inaplicáveis à realidade (TRICART, 1977).

Para Coltrinari (ibid.) o aspecto morfogenético, ou seja, o relativo à natureza genética das formas, deve aparecer claramente através da representação dos processos que as originaram e das formações superficiais correlativas. Esses materiais representam, ao mesmo tempo, um testemunho de processos presentes ou passados e uma condicionante da morfogênese, por apresentarem características intrínsecas que interferem na atuação da dinâmica atual.

Sob o ponto de vista cronológico, as formas devem ser localizadas no tempo tão exatamente quanto possível, fazendo aparecer às associações de feições desenvolvidas em diferentes fases da evolução da área. Poderão, assim, aparecer na carta gerações de formas 
sucessivas, em especial aquelas mais recentes, que se desenvolvem às custas das mais antigas, devendo ficar clara a distinção entre formas funcionais e dinâmicas e formas herdadas ou fixas (paleoformas) (TRICART, ibid.)

\section{METODOLOGIA}

A metodologia da pesquisa baseia-se nas recomendações da União Geográfica Internacional que estipula a morfometria, a morfologia, a gênese e a cronologia relativa como critérios fundamentais para a elaboração dos mapeamentos geomorfológicos.

\section{RESULTADOS PRELIMINARES}

$\mathrm{Na}$ área de estudo foram verificadas as seguintes formas de planície: a) Terraços aluvionares e seus subníveis (T1, T2 e T3); colúvios-alúvios no contato das áreas-fonte de sedimentos e seus subníveis (C1, C2 e C3); e meandros abandonados.

QUADRO: CRITÉRIOS ESTABELECIDOS PARA O MAPEAMENTO DAS PLANÍCIES FLUVIAIS DA BACIA DO RIO PEQUENO, ANTONINA-PR.

\begin{tabular}{|c|c|c|c|c|}
\hline $\begin{array}{c}\text { Unidade } \\
\text { Mofoescultural }\end{array}$ & Morfometria & $\begin{array}{l}\text { Sistema } \\
\text { Fluvial }\end{array}$ & Morfologia & $\begin{array}{c}\text { Características } \\
\text { Sedimentológicas }\end{array}$ \\
\hline $\begin{array}{l}\text { Planície dos } \\
\text { Canais } \\
\text { Principais } \\
\text { Planícies } \\
\text { Secundárias }\end{array}$ & $\begin{array}{l}\text { Dados } \\
\text { quantitativos }\end{array}$ & $\begin{array}{l}\text { Área fonte, } \\
\text { canais } \\
\text { tributários, } \\
\text { canal } \\
\text { principal }\end{array}$ & $\begin{array}{l}\text { Rampas de colúvio em } \\
\text { níveis diferentes (C1, } \\
\text { C2,); Terraços fluviais } \\
\text { (T1, T2 e T3);Meandros } \\
\text { abandonado; Várzeas; } \\
\text { Lagoas e Lineamentos }\end{array}$ & $\begin{array}{l}\text { Aloestatigrafia, } \\
\text { granulometria, } \\
\text { presença de linhas de } \\
\text { seixo, } \\
\text { pedoestatigrafia } \\
\text { associada(solos } \\
\text { enterrados) }\end{array}$ \\
\hline
\end{tabular}

\section{BIBLIOGRAFIA}

CHRISTOFOLETTI, A. Geomorfologia. São Paulo: Edgar Blucher, 1980.

COLTRINARI, L. Um exemplo de carta geomorfológica de detalhe: a carta do médio vale do Rio Parateí, SP (1:25.000). São Paulo: Orientação, 1982.

DEMEK, J. Generalization of geomorphologiacalmaps. In Progress Made in Geomorphological Mapping. Brno, 1967.

TRICART, J. Príncipes et méthodes de la geomorphologie. Paris: Massog et Cie Editeurs, 1965

TRICART, J. Ecodinâmica. Rio de Janeiro: FIBGE, 1977.

Palavras-chave: Planícies aluviais, Cartografia Geomorfológica, Gênese de relevo. 